\title{
A case of carbamazepine-induced pancreatitis
}

\author{
Ruijie Luo* \\ Department of Integrated Traditional Chinese and Western Medicine, West China Hospital, Sichuan University, Sichuan-610041, P.R. China
}

\begin{abstract}
There are many etiologies of acute pancreatitis, including gallstone, hyperlipidemia, drugs, alcohol, trauma, etc. In the clinical work, drug-induced acute pancreatitis cases are so many, but the etiology is often ignored by doctors. This paper reports a case of lipid metabolic abnormalities caused by carbamazepine, which also leaded to hyperlipidemia, so as to induce acute pancreatitis.
\end{abstract}

\section{Pancreatitis}

Acute pancreatitis is one of clinical common acute abdominal pain. Severe acute pancreatitis in the whole is accounted for $10 \%$ to $20 \%$ of acute pancreatitis, with a greater risk of disease, with many complications and progress rather quickly, high mortality; and clinical often is with systemic inflammatory response syndrome and multiple organ failure.

Of the various etiologies of abdominal pain, pancreatitis represents a specific pathology with various causes. A rare yet often overlooked cause of pancreatitis known as drug-induced pancreatitis is described by the author herein.

\section{Case study}

\section{Chief complaint}

A 52-year-old man was with the severe left upper quadrant (LUQ) abdominal pain ten hours.

\section{History of present illness}

The patient complained of pain that differentiated between sharp and dull aching in the LUQ abdominal area for 10 hours' duration. The patient also complained of consistent fevers ranging between $36.2^{\circ} \mathrm{C}$ $\left(97.2^{\circ} \mathrm{F}\right)$ and $37^{\circ} \mathrm{C}\left(98.6^{\circ} \mathrm{F}\right)$. The patient stated the pain increased after any food or oral intake and was mildly relieved with positional change (sitting up). The patient stated she was unable to sleep in bed for the past ten hours secondary to being unable to lie down because of sharp pain. The patient said he had the same symptoms 2 years prior that selfresolved within 7 days [1-6].

\section{Past medical history}

The patient had a medical history of epilepsy for 20 years, since 1995. In 2002 for the right occipital arteriovenous fistula in patients was with surgical treatment. In surgical resection, the doctors found a tumor at the occipital posterolateral about three by three by two centimeters size, his postoperative pathological results proved that the tumor was the arteriovenous malformation. He had been oral carbamazepine to control epilepsy after discharge. This patient's the first round with acute pancreatitis was in 2005, and had a diagnosis of hyperlipidemia, so we might confirm this for hyperlipidemia in patients with pancreatitis. Two years ago, he had abdominal pain, and suited the oral gastric medicine, and then he did feel better, but had not a definitive diagnosis. In 2006, he was with diagnosis of gallbladder stone, and did cholecystectomy. He denied any other medical problems [6-10].

\section{Current medications}

In 1995, this patient was with diagnosis of epilepsy, but did not cure. Since 2002, he had been using carbamazepine to control epilepsy, which dosage was one tablet each time, 3 times a day.

\section{Past medical history}

Allergies: The patient denied any allergies to food and medications.

Immunizations: The patient's history of vaccination was unknown.

Past hospitalizations/surgeries: In 2002 for the right occipital arteriovenous fistula in patients was with surgical treatment. In 2006, he was with diagnosis of gallbladder stone, and did cholecystectomy.

\section{Social history}

The patient worked at government in a small town. He got married at the age of 23. So far, he had got smoking and drinking 17 years, but his drinking could' t be more than one hundred milliliter every day, his smoking rarely was more than ten cigarettes every day. He had given up smoking and drinking for thirteen years.

\section{Family history}

The patient's parents had no history of diabetes, hypertension, and epilepsy. The patient was unsure of past familial cancer history.

\section{Review of systems}

A review of systems can be found in Table 1.

Correspondence to: Ruijie Luo, Department of Integrated Traditional Chinese and Western Medicine, West China Hospital, Sichuan University, Sichuan-610041, P.R. China, Tel: +86-28-13881919113; Fax: +86-28-82726906, E-mail: 13881919113@163.com

Key words: carbamazepine, hyperlipemia, acute pancreatitis

Received: June 03, 2017; Accepted: June 22, 2017; Published: June 24, 2017 


\section{Physical examination}

The patient was awake, alert, and oriented to time, name, and location. The patient was sitting in the chair beside the stretcher secondary to pain when lying down. The patient was actively guarding the left upper quadrant.

\section{Vital signs}

Temperature $36.7^{\circ} \mathrm{C}\left(98.1^{\circ} \mathrm{F}\right)$. Blood pressure was $139 / 85 \mathrm{mmHg}$ and heart rate was normal at 70 beats per minute. The patient's respiratory rate was 20 . Pulse oximetry was $100 \%$ on room air. Pertinent physical examination findings are shown in Table 2 [11-15].

\section{Differential diagnoses}

Differential diagnoses for left upper quadrant pain and fever include bowel obstruction, splenic infarct, infectious mononucleosis, splenic rupture, gastritis, gastric carcinoma, hiatal hernia, pancreatitis, pancreatic cancer, pancreatic cyst, pyelonephritis, renal calculus, and perinephric abscess (Collins).

\section{Review of this patient with hyperlipidemic pancreatitis etiology}

When patient was with abdominal pain clinic, checked blood triglycerides tendency for 15.3 millimoles per liter. So, we determined the cause of the patients with acute pancreatitis was hyperlipidemia.

\section{Clinical presentation}

When this patient arrived at our hospital, he was nausea, vomiting, and unbearable abdominal pain, at the same time there was shit unanswered and less urine volume. The patient admitted to hospital after 1 hour, had epileptic seizures. In addition, this patient was with no other symptoms.

Table 1. Patient review of systems.

\begin{tabular}{|l|l|}
\hline \multicolumn{1}{|c|}{ General } & \multicolumn{1}{c|}{ Denied any weight loss or gain. } \\
\hline Derm & $\begin{array}{l}\text { Denied any rash, lesions, or masses. } \\
\text { Eyes/Ears/Nose/Mouth/Throat Denied any headaches, dizziness, } \\
\text { visual disturbance, epistaxis, or recent upper respiratory infection. }\end{array}$ \\
\hline Cardiovascular & $\begin{array}{l}\text { Denied any chest pain, dyspnea on exertion, orthopnea, nocturnal } \\
\text { paroxysmal dyspnea, edema, cyanosis, hypertension, heart } \\
\text { murmurs, varicosities, phlebitis, or claudication. }\end{array}$ \\
\hline Respiratory & $\begin{array}{l}\text { Denied any shortness of breath, wheezing, stridor, cough, } \\
\text { hemoptysis, respiratory infections, or exposure to tuberculosis. }\end{array}$ \\
\hline Gastrointestinal & $\begin{array}{l}\text { Appetite decreased. Intermittent abdominal pain, intermittent } \\
\text { nausea, and no recent changes in bowel habits. }\end{array}$ \\
\hline Genitourinary & $\begin{array}{l}\text { No urgency, frequency, dysuria, nocturia, hematuria, polyuria, or } \\
\text { oliguria. }\end{array}$ \\
\hline Musculoskeletal & $\begin{array}{l}\text { No pain, swelling, redness or heat of muscles or joints, limitation, } \\
\text { of motion, muscular weakness, atrophy, or cramps. }\end{array}$ \\
\hline Neurologic & $\begin{array}{l}\text { No seizures, tremors, incoordination, parathesias, difficulties with } \\
\text { memory of speech, sensory or motor disturbances, or muscular } \\
\text { coordination (ataxia, tremor). Predominant mood "nervousness" } \\
\text { (define), emotional problems, and anxiety. }\end{array}$ \\
\hline
\end{tabular}

\begin{tabular}{|l|l|}
\hline \multicolumn{1}{|c|}{ General } & \multicolumn{1}{c|}{$\begin{array}{c}\text { Skin hot, dry, and pink. No cyanosis, pallor, jaundice, rashes, } \\
\text { or lesions. }\end{array}$} \\
\hline HEENT & No lymphadenopathy. Normal \\
\hline Pulmonary & Lung sounds clear to auscultation in all fields. \\
\hline Cardiac & + S1 +S2. Regular rate and rhythm (RRR). No murmurs or gallops. \\
\hline Gastrointestinal & $\begin{array}{l}\text { Abdomen mildly distended. No masses. Normoactive-bowel sounds } \\
\text { auscultated in all quadrants. Negative Murphy's Sign. No } \\
\text { organomegaly. No peritoneal signs. Patient guarding and tender over } \\
\text { left upper quadrant. }\end{array}$ \\
\hline Back & No costovertebral angle (CVA) tenderness. \\
\hline Musculoskeletal & No costoverteberal angle tenderness. \\
\hline
\end{tabular}

\section{Physical examination}

The patient with abdominal slightly raised, abdomen was not soft. The upper abdomen was tenderness obviously, and obvious rebound tenderness. His abdomen was without shifting dullness, and bowel sounds. In addition, this patient was without any other positive signs.

\section{Laboratory evaluation}

A variety of diagnostic laboratory tests assist in the diagnosis of both acute and chronic pancreatitis. Amylase has historically been the predominant marker when assessing for assumed pancreatitis. An amylase level 3 times the upper limit of normal has a high specificity for acute pancreatitis.

\section{Computed tomography of the abdomen}

This patient did the first Computed Tomography of the Abdomen, when he could feel abdominal pain in the beginning. The first result was a Full Abdomen Scan Computed Tomography, it told us that acute pancreatitis and infiltrating fluid were around 12 bowel swelling thickening, adjacent pancreas below saw enlargement, fuzzy vessels; Splenic nodules was in shadow, properties to be determined; the liver parenchyma density decreased slightly, mild liver fatty might be infiltration, gallbladder did not see, according to the scanning inner bag slightly thickened [16-21].

\section{Ultrasound of the abdomen}

This Patients with abdominal exceeds tiped that: liver slightly enhanced density, pancreas and liver echo echo reduce owe evenly, big spleen; In the spleen had slightly strong echo tubercle - hemangioma. Gallbladder was excision. The right side pleural had effusion. The abdominal had cavity effusion.

\section{Discussion}

\section{Carbamazepine-induced Pancreatitis}

We aimed to strengthen the follow-up of patients with oral carbamazepine, esp ecially long-term monitoring of blood lipid levels. We hoped that through our efforts could reduce carbamazepine induced acute pancreatitis, at the same time reduce other diseases caused by the carbamazepine.

\section{Acknowledgment}

The authors thank Mr. Wu Wei for her assistance with literature arrangement.

\section{References}

1. Trivedi CD, Pitchumoni CS (2005) Drug-induced pancreatitis: an update. $J$ ClinGastroenterol39: 709-716.[Crossref]

2. Soman M, Swenson C (1985) A possible case of carbamazepine-induced pancreatitis. Drug IntellClin Pharm 19: 925-927.[Crossref]

3. Forte A, Gallinaro L, Montesano G, Turano R, Bertagni A, et al. (1996) A possible case of carbamazepine induced pancreatitis. RivEur Sci Med Farmacol18: 187-189.[Crossref]

4. Tsao CY, Wright FS (1993) Acute chemical pancreatitis associated with carbamazepine intoxication. Epilepsia34: 174-176.[Crossref]

5. Robbie MJ, Scurry JP, Stevenson P (1988) Carbamazepine-induced severe systemic hypersensitivity reaction with eosinophilia. Drug IntellClin Pharm 22: 783-784. [Crossref]

6. Diroff JS, Sanders NA, McDonough SP, Holt DE (2006) Gastrin-secreting neoplasia in a cat. J Vet Intern Med 20: 1245-1247.[Crossref]

7. Agency for Healthcare Research and Quality (2006) Nationwide Emergency Department Sample. Healthcare Cost and Utilization Project. 
8. Arvanitakis M, Delhaye M, De Maertelaere V, Bali M, Winant C, et al. (2004) Computed tomography and magnetic resonance imaging in the assessment of acute pancreatitis. Gastroenterology126: 715-723.[Crossref]

9. Balani AR, Grendell JH (2008) Drug-induced pancreatitis: incidence, management and prevention. Drug Saf31: 823-837.[Crossref]

10. Balthazar EJ, Robinson DL, Megibow AJ, Ranson JH (1990) Acute pancreatitis: value of CT in establishing prognosis. Radiology174: 331-336.[Crossref]

11. Cappell MS (2008) Acute pancreatitis: etiology, clinical presentation, diagnosis, and therapy. Med Clin North Am 92: 889-923.[Crossref]

12. Ju S, Chen F, Liu S, Zheng K, Teng G (2006) Value of CT and clinical criteria in assessment of patients with acute pancreatitis. Eur J Radiol57: 102-107.[Crossref]

13. Matull WR, Pereira SP, O'Donohue JW (2006) Biochemical markers of acute pancreatitis. J ClinPathol59: 340-344.[Crossref]

14. Munoz A, Katerndahl DA (2000) Diagnosis and management of acute pancreatitis. $\mathrm{Am}$ Fam Physician 62: 164-174.[Crossref]
15. Powers RD1, Guertler AT (1995) Abdominal pain in the ED: stability and change over 20 years. Am J Emerg Med 13: 301-303.[Crossref]

16. Scarpelli D (2001) The pancreas. In Rubin E (Ed), Essential Pathology (3rd Edn) Lippincott Williams \& Wilkins, Philadelphia, PApp. 441-450.

17. Smith RC, Southwell-Keely J, Chesher D (2005) Should serum pancreatic lipase replace serum amylase as a biomarker of acute pancreatitis? ANZ J Surg 75: 399-404. [Crossref]

18. Smotkin J, Tenner S (2002) Laboratory diagnostic tests in acute pancreatitis. $J$ ClinGastroenterol34: 459-462.[Crossref]

19. Soman M, Swenson C (1985) A possible case of carbamazepine-induced pancreatitis Drug IntellClin Pharm 19: 925-927.[Crossref]

20. Tchelepi H, Ralls P (2007) Ultrasound of acute pancreatitis. Ultrasound clinics3: 415 422 .

21. Whitcomb DC (2006) Clinical practice. Acute pancreatitis. N Engl J Med 354: 21422150.[Crossref]

Copyright: $\mathbb{C} 2017$ Luo R. This is an open-access article distributed under the terms of the Creative Commons Attribution License, which permits unrestricted use, distribution, and reproduction in any medium, provided the original author and source are credited. 